\title{
Fraud Specialists On Independent Audits
}

James A. Tackett, (E-mail: JamesATackett@aol.com), Youngstown State University

Fran M. Wolf, (E-mail: wolf1876@yahoo.com), Youngstown State University

Gregory A. Claypool, (E-mail: gregclaypool@yahoo.com), Youngstown State University

\begin{abstract}
The recent audit failures involving Enron, WorldCom, et al., have left the accounting profession and governmental regulators scrambling to find better methods of detecting and preventing fraudulent financial reporting. Congress passed the Sarbanes-Oxley Act of 2002 (SOX) which requires companies to report on the operating effectiveness of their internal controls over financial reporting. Additionally, the independent auditor is required to assess and report on the effectiveness of their client's internal controls, and they must attest to management's internal control assessment. Notably absent from SOX is a requirement that independent auditors must employ fraud specialists in their independent audits of SEC filers.
\end{abstract}

This study examines the benefits and costs associated with requiring the use of fraud specialists on independent audits of SEC filers. Fraud specialists have expertise better attuned to fraud detection not ordinarily possessed by regular auditors. First, the narrow but deep perspective of the fraud specialist enables them to find fraudulent activity that would be missed by regular auditors. Second, unlike regular auditors, fraud specialists employ methodologies that are effective in the presence of management collusion. They are more highly skilled at interviewing potential witnesses and fraud suspects and are trained in recognizing deception. Third, fraud specialists are better trained in the use of antifraud technology, methods, and computerized forensic accounting software. Fourth, fraud specialists have superior investigative skills and can conduct covert examinations, access restricted databases, conduct background checks, and locate hidden assets better than regular auditors. Finally, they understand the legalities of gathering evidence of fraud and can operate without violating the rights of potential witnesses and fraud suspects.

Qualitative analysis demonstrates that utilizing fraud specialists on independent audits has positive net benefits to financial reporting. Recommendations are made regarding the types of fraud detection/deterrence skills and techniques that would be beneficial to independent auditors.

\section{INTRODUCTION}

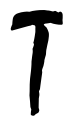

he recent auditing failures involving Enron, WorldCom, et al. have left the accounting profession and governmental regulators scrambling to find better methods of detecting and preventing fraudulent financial reporting. In 2002, Congress passed the Sarbanes-Oxley Act (SOX) requiring companies to report on the operating effectiveness of their internal controls over financial reporting. Additionally, SOX requires the independent auditor to assess and report on the effectiveness of their client's internal controls. Moreover, they must also evaluate and report on management's internal control assessment. These three reports involving internal control are at the crux of Congressional effort to deter massive auditing failures in publicly traded companies. Notably absent from SOX is the requirement that independent auditors must employ fraud specialists in their audit of SEC filers. Since the vast majority of auditing failures involve management fraud, the wisdom of not requiring fraud specialists on independent audits is open to question. This study examines the benefits and costs of requiring the use of fraud specialists on independent audits of SEC filers. 


\section{THE CAUSE OF AUDITING FAILURE}

Auditing failure occurs when management grossly misrepresents their financial statements and auditors, through negligence or incompetence, fail to discover and report these misrepresentations to the public. Congress has taken a largely unidimensional approach in trying to solve this problem with increased emphasis on internal control and internal control reporting. Unfortunately, massive internal control effort will not prevent auditing failure. Aside from auditor fraud or negligence, the primary cause of auditing failure involves management collusion. Management collusion renders internal controls over financial reporting relatively ineffective because management is working as a team to fake documents, alter records, and fabricate scenarios to fool the auditor into believing the financial statements are real. Accordingly, a key flaw in SOX concerns the observation that the effectiveness of its internal control reporting requirements is predicated on the absence of senior management collusion. Without senior management honesty, the purported benefit of internal control reporting in reducing the likelihood of auditing failure is largely an illusion.

A strong internal control system can deter individual acts of dishonesty because of the required segregation of duties. Unfortunately, the benefits of segregating duties along the lines of record-keeping, custodianship, and authorization evaporate when conspirators cross segregation lines to fabricate the internal control documentation for fraudulent accounting numbers. Management collusion can be deterred in some cases, but never completely eliminated. Accordingly, a central element in preventing auditing failures concerns the development of practical methods of detecting or deterring management collusion.

\section{ADVANTAGES OF THE FRAUD SPECIALIST}

Management collusion in financial reporting is at the focal point of almost all modern auditing failures. Deter or detect management collusion, and the vast majority of auditing failures are eliminated. Who is better able to deal with management collusion, regular auditors or fraud specialists?

\section{The Specialization Factor}

Regular auditors are generalists. They are required to have a broad knowledge of accounting, auditing, taxation, business law, federal and state reporting requirements, etc. This broad knowledge base is necessary in order to understand the wide range of business transactions, documents, and accounting entries contained in a typical audit. Regular auditors are also trained in detecting fraud (e.g., SAS 99), but this training is elementary and does not emphasize modern methods of dealing with collusion.

Fraud specialists have training that is narrow and deep. They are thoroughly familiar with the various methods of perpetrating a fraud, and they keenly appreciate and perceive possible opportunities to commit fraud. This specialized training enables the fraud specialist to find a wider variety of fraudulent schemes than a regular auditor. Moreover, the fraud specialist finds these schemes on a more timely basis. In the long-run, regular auditors find almost as many fraudulent schemes as fraud specialists. However, timeliness is an extremely important issue in fraud detection. All of the major auditing failures involve frauds that were eventually exposed, but this exposure came at a high cost to the financial markets and society. Utilizing fraud specialists on independent audits means finding more frauds on a more timely basis.

\section{The Collusion Factor}

When auditing failure occurs due to collusion, four factors are present. First, there is a conspiracy among members of management to misrepresent their financial statements. Second, accounting and business records are altered to conform with the misrepresented financial statements. Third, management makes written and verbal misrepresentations to the auditor supporting the altered accounting and business records. Finally, auditor negligence or incompetence fails to discover management's misrepresentations. The first three factors of auditing failure cannot be prevented because they are under the control of management. Accordingly, a critical element in preventing 
auditing failure concerns the manner in which auditors search for verbal and documental deception on the part of management.

Regular auditors typically have some basic training in detecting verbal and documental deception. However, their deception detecting skills are far below those of a fraud specialist. Skill in detecting forged, altered, or fabricated documents is critical to auditing because these documents provide evidence that a fraud was committed. Moreover, they are useful in determining the nature and scope of the fraud, and they can establish which parties are involved in the conspiracy (Wells, 2005). Generally, fraud specialists are not forensic document experts. However, they are superior to regular auditors in identifying suspicious documentation. Factors such as signatures, handwriting, erasures, paper and ink comparisons, typewriter or word processor characteristics etc. are considered by fraud specialists when identifying suspicious documents. Once suspicious documents are flagged, they can be further examined by a document expert for authenticity, fingerprints, indented writings, etc.

All auditors conduct interviews with management and their employees on a routine basis. In order to perpetrate the fraud, management must lie to their auditors about the authenticity of altered accounting and business records. Detecting verbal deception is a critical element in preventing auditing failure because it is frequently the auditor's last chance to spot anomalies that require further investigation. For example, the auditor finds a receiving report with missing information. The auditor makes inquiries about the report, and if the auditor is unable to detect the verbal deceptions of management, the report may be accepted as authentic.

Fraud specialists are superior to regular auditors in detecting verbal deception because they have extensive training in observing the behavioral symptoms exhibited by deceptive persons. The fraud specialist will generally begin the interview with small talk and light conversation. During this light conversation, the fraud specialist is discreetly observing the behavioral mannerisms of the subject (this is called calibration). After the subject is calibrated, the fraud specialist will slowly move to the salient points of the interview. If the behavioral mannerisms of the subject change when a critical topic is discussed, the fraud specialist will note this and mark this issue for deeper investigation. Observing a marked change in behavioral symptoms does not prove that the subject is lying. However, studies have shown that lying produces stress, and this stress is highly correlated with behavioral symptom changes (Inbau, 2005). Essentially, the fraud specialist is administering a legal, covert polygraph to the subject. The skills necessary to set up, administer, and evaluate this behavioral polygraph are well beyond those found in regular auditors, and requires the extensive preparation and training of fraud specialists.

The ability to quietly detect deception is a major factor that separates regular auditors from fraud specialists. When possible deception is indicated, the fraud specialist thanks the subject for their help, and ends the interview leaving the impression that all questions have been answered satisfactorily. The fraud specialist discreetly expands the scope of the investigation to determine whether or not deception has actually taken place. If deception has taken place, forensic accounting evidence is gathered to document the nature of the deception along with the parties that are involved.

\section{The Technology Factor}

Modern accounting and business records are largely computerized with digital documentation and authorization of business transactions. Computerization of business records creates special problems for auditors with respect to fraud detection. The detection of electronic erasures and document alterations requires sophisticated computerized knowledge on the part of the auditor. Regular auditors typically have enough computer knowledge to access business records, journal entries, electronic documentation, etc., but they lack advanced computer forensics training. On the other hand, fraud specialists regularly employ forensic accounting software and methods to detect computerized financial statement fraud. Examples include fraud data mining software (e.g., ACL), digital analysis (e.g., Benford's Law), autonomous suspicious activity logs, forensic software applications, etc. (Coderre, 2004).

Forensic software applications can monitor any unusual adjustments to computerized accounting records and documentation. These applications are similar to computerized internal controls, but there are some significant differences. Generally, forensic software creates a "forensic image" of computerized transactions, account balances, 
document files, etc. along with an activity log. This forensic image is created without utilizing the computer's operating system to prevent any alterations to the images that are being cloned (e.g., EnCase forensic software). Accordingly, evidence gathered under these circumstances is legally valid and admissible in a court of law (Casey, 2004). SOX requires management to design and implement their internal control system. Thus, management has a clear understanding of internal control strengths and weaknesses and can therefore use collusion to defeat it. Conversely, management is unaware of the methods used by forensic software and cannot easily disable or circumvent the software without auditor-management collusion. Accordingly, even in the presence of management collusion, the unauthorized or fictitious adjustment of accounting records is considerably more difficult if forensic software applications are employed in addition to management's internal controls over financial reporting.

\section{The Investigate Skill Factor}

Successful fraud detection frequently requires specialized investigative skills. Forensic accounting software, interviewing skills, and collusion expertise may highlight red flags of possible fraud, but they rarely make a prima facie fraud case. In order to prove fraud, there is frequently the need to trace illicit transactions or locate hidden assets. Regular auditors can comfortably follow the "paper trail" for regular business transactions. However, they lack the investigative skills of fraud specialists when it comes to conducting background investigations, covert examinations, discovering false identities, etc.

Fraud specialists are familiar with the various asset-hiding techniques utilized by perpetrators. They know how to utilize the legal system to subpoena bank records, credit reports, and private business records that support a successful fraud investigation. Fraud specialists can conduct covert operations involving electronic or video surveillance, and they understand how to utilize informants, public legal records, and restricted databases such as ChoicePoint to gather the necessary information that establishes a fraud case. This investigative information is also useful for extracting confessions from fraud perpetrators. Accordingly, all documental, electronic, video, etc. elements of the investigation should be completed before seeking an admission of guilt from a suspected perpetrator. Fraud specialists have the same basic accounting and auditing skills as regular auditors, but also include the necessary legal and detective skills that are necessary in proving that occupational fraud exists.

\section{The Legal Factor}

Regular auditors have significant legal training in business law to provide a basis for understanding business transactions. However, they generally have a poor understanding of legal evidence, rights of suspects, the courts, criminal law, etc. This lack of understanding of the criminal legal system can provide a debilitating blow to the auditor's ability to detect fraud. For example, regular auditors do not seek an admission of guilt from fraud suspects due to possible litigation in the form of defamation, false imprisonment, trespass, invasion of privacy, public disclosure of private information, etc. Investigating fraud is a quagmire of legal traps and pitfalls that can result in unnecessary litigation or fraud perpetrators evading the legal system (Squires, 2004). Accordingly, regular auditors are at a significant disadvantage when dealing with fraud suspects, and the limitations on what they can say and do significantly restricts their ability to find fraud.

Conversely, fraud specialists are trained in the criminal legal system and can operate without violating the rights of potential witnesses and fraud suspects. They understand the legalities of gathering evidence of fraud. Legal issues regarding the chain of custody of documents, admissibility of evidence, etc. are understood. Interviews are conducted in a manner that prevents successful defamation litigation against the auditor or client regarding allegations of fraud or illegal activities. In some cases the litigation resulting from a sloppy fraud investigation can be more damaging than the fraud itself. Fraud specialists are trained to accomplish their mission of finding fraud without triggering unnecessary legal complications.

\section{LIMITATIONS OF FRAUD SPECIALISTS}

Aside from the significant monetary cost of employing fraud specialists and their sophisticated methodologies, there are disadvantages related to implementation and mission. First, while fraud specialists are 
superior to regular auditors in detecting falsified financial statements, the difference may not be significant in many auditing situations. If management perpetrates a sloppy or unsophisticated fraud, then regular auditors are able to detect this without difficulty. Since the majority of management frauds are rather unsophisticated, the services of a fraud specialist may be unnecessary most of the time. Second, the mission of the independent auditor is to determine whether the financial statements are fairly presented, not to detect or build a case for prosecuting embezzlement or asset misappropriation. Many of the skills of the fraud specialist are more attuned to loss prevention, or defalcation detection. Loss prevention is important for SEC filers, but it does not directly relate to the mission of the independent auditor. Summarizing the disadvantages of fraud specialists, they are expensive, and their specialized skills may be overkill for many auditing situations.

\section{NET BENEFITS OF FRAUD SPECIALISTS}

One could argue that employing fraud specialists on independent audits is unnecessary because sophisticated financial statement frauds are rare. However, this position fails to recognize that when they do occur, undetected financial statement frauds are very costly to society. Also, many large auditing failures occurred via simple frauds where the auditor inexplicably failed to detect the fraud on a timely basis (e.g., ESM Securities, ZZZZ Best Co., Crazy Eddie, Lincoln Saving and Loan, etc.). The critical question concerns whether the value of employing fraud specialists on independent audits exceeds their associated cost. Qualitatively, this value involves the increased fraud detection and deterrence capability of fraud specialists matched against their monetary cost. Consider the enormous cost of internal control reporting under SOX (i.e., Section 404) combined with the prior observation that such internal control reporting is relatively ineffective in preventing collusion based financial statement fraud. Employing fraud specialists on independent audits would cost only a fraction of what is currently expended on SOX compliance, and would likely be more effective in preventing collusion based auditing failure.

\section{SUMMARY AND CONCLUSIONS}

SEC filers are typically large and complex business entities that are rife with opportunities for occupational fraud. Even with the internal control reporting requirements of Sarbanes-Oxley, significant opportunities for financial statement fraud exists because of management collusion. The addition of fraud specialists to the audit team adds a significantly increased improvement in fraud detection capability. Superior technological skill, legal training, investigative skill, and collusion detection methods enable fraud specialists to outperform regular auditors in detecting defalcation and fraudulent financial statements. Requiring fraud specialists on all independent audits of SEC filers is a cost-effective way to mitigate the likelihood of major auditing failure in publicly traded companies.

\section{REFERENCES}

1. $\quad$ Casey, E. (2004), Digital Evidence and Computer Crime, $2^{\text {nd }}$ Ed., Elsevier Academic Press, London. pp. 220228.

2. Coderre, D. (2004), Fraud Detection, Data Analysis, Techniques \& Methods, Ekaros Analytical, Inc., Vancouver, British Columbia.

3. Inbau, F., Reid, J., Buckley, J., and Jayne, B. (2005), Criminal Interrogation and Confessions, Jones and Bartlett Publishers, Sudbury, MA.

4. Public Law 107-204, Sarbanes-Oxley Act of 2002, H.R. 3763, $107^{\text {th }}$ Congress of the United States of America.

5. Squires, D. (2004), Legal and Practical Issues Related to Fraud Examination”, ACFE $15^{\text {th }}$ Annual Conference, Las Vegas, NV, July.

6. Statement on Auditing Standards No. 99, (2002), Consideration of Fraud in a Financial Statement Audit. American Institute of Certified Public Accountants, Inc., New York, New York.

7. Wells, Joseph T., Principles of Fraud Examination, (New Jersey: John Wiley \& Sons, 2005) p.13-21. 
NOTES 